\title{
Globe
}

Revue internationale d'études québécoises

\section{Jacques Michon, Les éditeurs québécois et l'effort de guerre (1940-1948), Québec et Montréal, Les Presses de l'Université Laval et BAnQ, 2009}

\section{Yvan Lamonde}

Volume 13, numéro 1, 2010

Culture et relations internationales

URI : https://id.erudit.org/iderudit/044646ar

DOI : https://doi.org/10.7202/044646ar

Aller au sommaire du numéro

Éditeur(s)

Globe, Revue internationale d'études québécoises

ISSN

1481-5869 (imprimé)

1923-8231 (numérique)

Découvrir la revue

Citer ce compte rendu

Lamonde, Y. (2010). Compte rendu de [Jacques Michon, Les éditeurs québécois et l'effort de guerre (1940-1948), Québec et Montréal, Les Presses de l'Université Laval et BAnQ, 2009]. Globe, 13(1), 175-176. https://doi.org/10.7202/044646ar d'utilisation que vous pouvez consulter en ligne.

https://apropos.erudit.org/fr/usagers/politique-dutilisation/ 


\section{Jacques Michon \\ Les éditeurs québécois et l'effort de guerre (1940-1948), Québec et Montréal, Les Presses de l'Université Laval et BAnQ, 2009.}

Un sujet bien dominé, une conception graphique remarquable et la proposition de facto de nouvelles normes dans la publication de catalogues d'expositions me semblent pouvoir résumer l'intérêt exceptionnel de cet ouvrage, un catalogue d'exposition qui expose de façon exceptionnelle un moment de l'histoire du livre et de la culture en temps de guerre.

Jacques Michon travaille depuis près de trente ans sur l'histoire de l'édition québécoise et il a fait le point sur la période couverte dans le tome II de son Histoire de l'édition littéraire au Québec au XX' siècle (Le temps des éditeurs, 1940-1959, Fides, 2004). Cette familiarité de fond avec le sujet lui permet d'aller à l'essentiel, de ne pas tomber dans l'anecdotique ou le sensationnel. La force de son travail comme commissaire de l'exposition qui s'est tenue à la Bibliothèque nationale du Québec du 22 septembre 2009 au 28 mars 2010 réside dans l'aisance avec laquelle est conduite la contextualisation des textes et des ouvrages. Outre le fait qu'il donne toute sa dimension à un phénomène peu connu, l'ouvrage insère l'édition dans la question des relations entre le Québec et la France, à un moment où ces relations se transforment en une autonomie plus grande des Canadiens français à l'égard de la France.

Une fois l'arrêté ministériel fédéral voté - mais qui s'en fait l'initiateur? - qui allait assurer la tenue des comptes en matière de droits d'auteurs, Jacques Michon fait voir comment les libraires grossistes, puis des maisons d'édition déjà fondées - Fides, Bernard Valiquette - ou qui se fondent - les Éditions de l'Arbre de Robert Charbonneau et Claude Hurtubise, les Éditions Variétés de Paul Péladeau et André Dussault - occupent le créneau laissé inopérant par les éditeurs français confrontés à la censure et au manque de papier. Plaque tournante de l'édition d'ouvrages en français pour New York, Rio de Janeiro et Mexico, Montréal voit se multiplier les éditeurs: Lucien Parizeau, Serge Brousseau, Fernand Pilon, Gérard Dagenais, Berthe Dulude Simpson. Le décollage de l'édition est tel qu'on crée la Société des éditeurs canadiens du livre français (1943). Auteurs, éditeurs, imprimeurs, artistes (Pellan, La Palme, Fernand Léger) et graphistes animent ce monde prospère de la culture en pleine guerre. 
L'après-guerre, avec des initiatives d'éditeurs comme la venue de Sartre ou de Lévi-Strauss à Montréal, connaît des lendemains qui chantent moins. La ressaisie du clergé canadien-français, l'inaction du gouvernement de Maurice Duplessis, réélu en 1944 après une éclipse de cinq ans, et la nonréception du livre canadien en France, voire l'agressivité d'un certain milieu, auquel Robert Charbonneau répond dans La France et nous (1947), secouent le monde de l'édition qui revient presque à la case de départ.

À ce travail de mise en place des connaissances sur le sujet s'ajoute une exceptionnelle créativité en matière de graphisme. La présentation du catalogue, la géniale utilisation pour la couverture d'une affiche de guerre où les baïonnettes sont remplacées par des livres, la mise en caractères plus gros et en rouge des premiers mots des paragraphes comme dans l'enluminure médiévale, les notes de bas de pages regroupées de façon originale tout comme les références bibliographiques compactées d'une manière fonctionnelle poussent le lecteur à aller voir qui est responsable de ce coup de maître. Il s'agit de orangetango, une agence multimédia maintes fois primée de Montréal.

La qualité du travail scientifique et l'inventivité graphique contribuent à la mise en place d'une nouvelle norme d'excellence, d'une nouvelle référence en matière de publication. À nouveau, BAnQ repousse les limites et fait comprendre, après «Le moulin à images» de Robert Lepage, que l'histoire contemporaine, celle du XXI ${ }^{e}$ siècle, doit se faire avec le visuel.

Yvan Lamonde Université McGill

\section{Joe King \\ Fabled City: the Jews of Montreal, Montréal, Price-Patterson, 2009.}

Dans sa plus récente publication, Joe King, journaliste et animateur montréalais de longue date, nous offre un ouvrage divertissant et informatif sur la communauté juive de Montréal. Le livre Fabled City: the Jews of Montreal est le dernier d'une trilogie sur l'histoire de la communauté. Il fut précédé de From the Ghetto to the Main (2000) et de From Baron Byng to Bagels (2006). Se faisant, King confirme sa renommée de conteur et d'homme d'information au sein de la communauté juive montréalaise. 